\title{
Mobilização política e rede de interesses na produção calçadista de Jaú
}

\section{Political mobilization and interests in the Jaú's footwear production}

\author{
Guilherme Augusto Malagolli' \\ Luiz Fernando de Oriani Paulillo²
}

\begin{abstract}
Resumo: O estudo de redes políticas é de fundamental importância para a compreensão do ambiente em que ocorre a interação estratégica dos atores e organizações dependentes de vários recursos, como os financeiros, tecnológicos, organizacionais, políticos, jurídicos e constitucionais. A aplicação do estudo de redes políticas em Arranjos Produtivos Locais (APLs) pode explicar o desenvolvimento econômico e social do território pela formulação de políticas adotadas localmente. Este trabalho tem como objetivo mostrar a relevância da análise da rede política no estudo de Arranjos Produtivos Locais, tomando como objeto de estudo o APL calçadista de Jaú. Para isso, foi feita uma pesquisa de campo, por meio de um questionário semiestruturado, com empresas, entidades de classe e representantes do poder público local no APL calçadista de Jaú.
\end{abstract}

Palavras-chave: Rede política. Institucionalismo. Arranjos Produtivos Locais. Território. Calçados. Governança.

\begin{abstract}
The study of policy network is crucial to understand the environment in which strategic interaction between actors and organizations take place, and it depends upon various resources such as financial, technological, organizational, political, legal, and constitutional. The implementation of network policy studies in Clusters (LPAs) can explain their economic and social development through the formulation of policies that are adopted locally. This paper aims to show the relevance of policy network analysis in the study of Local Productive Arrangements'focusing on the LPA of the city of Jau's. Therefore, a field research was carried out using a semi-structured questionnaire to investigate companies, unions, and local government representatives in the LPA of Jau's footwear industry.
\end{abstract}

Keywords: Policy network. Institutionalism. Local Productive Arrangements. Territory. Footwear. Governance.

\section{Introdução}

A literatura que estuda as aglomerações geográficas de empresas mostra que as empresas pertencentes a Arranjos Produtivos Locais (APLs), tanto de países desenvolvidos como de países emergentes, são capazes de obter vantagens competitivas em relação às empresas dispersas geograficamente (LOMBARDI, 2003). Segundo Garcia, Motta e Amato Neto (2004), as vantagens competitivas das empresas em aglomerações industriais são de duas naturezas: as economias externas puras, de caráter incidental, e as ações conjuntas que são estabelecidas pelos agentes econômicos.

As vantagens comuns, obtidas com a aglomeração geográfica de empresas do mesmo setor, levam os agentes envolvidos a estabelecerem interações estratégicas para alcançarem estas vantagens. $\mathrm{O}$ conjunto de interações entre os agentes pode configurar uma rede social, econômica e política. Este trabalho está centrado na ideia de que APLs podem conter e mesmo operar redes políticas para o processo de coordenação.

Analisar a existência de uma rede não é uma tarefa trivial. Estas redes são influenciadas por fatores como a restrição imposta pelas regras e normas, a representação e distribuição dos interesses dos atores e a distribuição dos recursos de poder. Assim, uma rede política gera uma estrutura de governança composta por três elementos: interesses, oportunidades de ação e recursos de poder (NAVARRO YÁÑES, 1999; PAULILLO, 2002).

Desta forma, diversos aspectos das interações devem ser levados em consideração na tentativa de identificação de uma rede. A literatura acerca da formação de redes é gerada em diversos campos

\footnotetext{
${ }^{1}$ Departamento de Engenharia de Produção, Universidade Federal de São Carlos - UFSCar, CEP 13565-905, São Carlos, SP, Brasil, e-mail: gmalagolli@uol.com.br

${ }^{2}$ Programa de Pós-graduação em Engenharia de Produção, Universidade Federal de São Carlos - UFSCar, Rod. Washington Luís, Km 235, CP 676, CEP 13565-905, São Carlos, SP, Brasil, e-mail: dlfp@ power.ufscar.br
}

Recebido em 28/12/2012 — Aceito em 9/5/2012

Suporte financeiro: Nenhum. 
do conhecimento, como o econômico, sociológico, político, etc. A rede política, no entanto, pode permear todas estas ações de interação (Uma rede política influencia diretamente as ações dos agentes facilitando ou dificultando a realização de tarefas estabelecidas. Segundo Santos (2002), a rede política cria uma situação de interdependência entre os agentes na formulação de políticas de interesse em comum).

Este trabalho tem por objetivo mostrar a relevância da análise da rede política no estudo de Arranjos Produtivos Locais, tomando como objeto de estudo o APL calçadista de Jaú. A hipótese central é a de que uma rede se desenvolve com intensa mobilização política no APL de Jaú. Para isso, foram definidas quatro dimensões de análise: atores, distribuição de poder, estratégia dos atores e integração política, conforme detalhado na metodologia de pesquisa.

\section{Abordagem de redes}

A abordagem de redes é fundamental para que se possa compreender melhor o dinamismo e as eventuais diferenciações das interações entre os agentes. Autores como Powell e Smith-Doer (2003) definem uma rede como um conjunto de atores, quer sejam indivíduos ou organizações, com tipos específicos de conexões uns com os outros. A análise da composição da rede e a posição ocupada por cada ator permite e a análise da composição da rede permite compreender aspectos do convívio econômico, social e político dos agentes (POWELL; SMITH-DOER, 2003).

Segundo Paulillo (2001), a rede é o locus no qual podem ser elaboradas as políticas públicas e os processos de concorrência. É neste ambiente que ocorre a interação estratégica dos atores e organizações, que são dependentes de vários recursos, como os financeiros, tecnológicos, organizacionais, políticos, jurídicos e constitucionais. Este enfoque está vinculado ao quadro teórico do neoinstitucionalismo do pluralismo reformado, em que se observa um papel muito particular do Estado, como agente fragmentado e com interesses específicos.

De um modo geral, o pluralismo reformado analisa principalmente o processo de interação de atores sociais e econômicos em contextos democráticos e de forte liberalização econômica, na qual há a fragmentação do Estado, o avanço da globalização e a complexidade da sociedade civil. Esta perspectiva é de grande relevância neste trabalho, pois se considera que a capacidade do Estado para a resolução dos problemas está fragmentada - em setores, subsetores, agrupamentos complexos, etc. Nesses casos, o Estado não é neutro e as agências estatais (secretarias, comissões, agências regulatórias, etc.) participam do processo de interação representando interesses e disputando ou distribuindo recursos de poder com os demais atores. É neste quadro que se pode trabalhar com as ações dos atores coletivos e individuais, o mecanismo de governança e o ambiente institucional. (PAULILLO, 2001, p. 252-253).

Neste contexto, a literatura traz duas abordagens principais acerca da abordagem de redes: redes como forma de governança e redes como forma de análise. A abordagem de redes como forma de governança apresenta um enfoque produtivo para o estudo do tema. As redes são dinâmicas, relacionadas com a mudança contínua de atores e interesses. Neste aspecto, destacam-se como fatores fundamentais de análise da rede a aprendizagem, cooperação, reciprocidade, controle e reputação (HALL, 1999).

Segundo Powell e Smith-Doer (2003), na abordagem como formas de governança, as redes funcionam como um mecanismo de coordenação das relações entre os agentes econômicos visando proporcionar a maior taxa de retorno, por meio da redução dos custos e do acesso a recursos diferenciados que resultariam em níveis de produtividade maiores do que se estivessem agindo isoladamente.

$\mathrm{Na}$ abordagem de redes como forma de análise, o enfoque está na natureza das redes e na estrutura de influência das relações entre os agentes, que estimulam ou inibem a ocorrência de fatos tangíveis, como a geração de emprego e avanços tecnológicos, e intangíveis, como ideias e comportamentos. Desta forma, enquanto a abordagem de redes como formas de governança concentra-se nas estruturas de relações econômicas entre os atores da rede, mais prescritiva e multidisciplinar, a abordagem de redes como forma de análise está baseada na sociologia e na teoria organizacional, concentrando-se nas relações sociais entre os agentes, nas relações intraorganizacionais, avaliando como as relações ocorrem e de que forma influenciam a vida dos atores (POWELL; SMITHDOER, 2003).

A abordagem de redes como forma de análise está fundamentada na estrutura das relações para compreender uma ampla gama de aspectos. Para esta abordagem, o ambiente social pode ser visto como estruturas ou relações regulares entre os agentes. As relações são expressas por meio dos elos, conexões (linkages) ou ligações entre as unidades de análise. Por meio dos linkages fluem recursos materiais e não materiais, interação física dos atores e as relações formais de autoridade (SACOMANO NETO, 2003; WASSERMAN; FAUST, 1994).

Neste sentido, Brito (2002), afirma que uma rede é composta por quatro elementos morfológicos: nós, posições, ligações e fluxos (Figura 1). Os nós podem ser descritos como um conjunto de agentes, objetos ou eventos presentes na rede. São os nós que compõem a estrutura e podem ser considerados pontos focais da rede. Da mesma forma, as atividades podem ser 


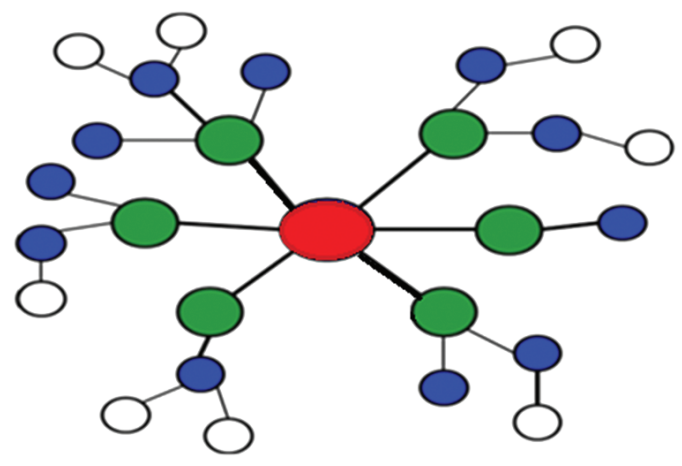

NÓS - Os nós podem ser representados por uma empresa ou uma atividade entre empresas. Na figura, os nós são representados pelos pontos.

POSIÇÕES - A posição de um ator na rede é compreendida pelo conjunto de relações estabelecidas com os outros atores da rede. As diferentes cores dos atores da figura mostram as diferentes posições estruturais ocupadas pelos atores na rede.
LIGAÇÕES (Linkages) - As ligações ou conexões de uma rede são compreendidas na figura pelos traços entre os atores. As diferentes espessuras mostram diferenças na qualidade do relacionamento entre os atores.

FLUXOS - Por meio das ligações, fluem recursos, informações, bens, serviços e contatos. Os fluxos podem ser tangíveis e intangíveis.

Figura 1. Elementos morfológicos da rede. Fonte: Elaborado pelo autor a partir de Sacomano Neto (2003).

consideradas pontos focais do arranjo. As posições definem a localização dos pontos na estrutura da rede. A posição de cada ponto depende das ligações e da divisão do trabalho de cada agente. As ligações, conexões e linkages determinam o grau de difusão ou densidade dos atores da rede. Os fluxos, por sua vez, podem ser tangíveis (insumos e produtos) ou intangíveis (informações) e determinam a estrutura da rede (BRITO, 2002; SACOMANO NETO, 2003).

As duas abordagens de rede, no entanto, apresentam grande interface e semelhanças conceituais, de forma que a sua distinção na prática seja sutil. A abordagem de rede como forma de análise está mais vinculada à produção acadêmica americana e inglesa, enquanto a abordagem de forma de governança é associada a pesquisadores da Europa continental, principalmente Espanha e Alemanha. Segundo Börzel (1997), não há na literatura uma clara distinção entre as duas abordagens, considerando serem ambas não excludentes, uma vez que compartilham de uma temática comum de investigação: a de como a configuração da rede influencia a elaboração de políticas públicas.

No entanto, conceitualmente, se identificam três tipos de redes: redes econômicas, redes sociais e redes políticas. A diferenciação entre estes tipos depende de fatores que influenciam as ações dos agentes e/ou fatores que caracterizam o contexto. Entre estes fatores, destacam-se: 1) as restrições impostas pelas regras ou normas; 2) a representação e distribuição dos interesses dos atores; e 3) a distribuição dos recursos de poder.
Estes fatores, associados entre si em uma rede, geram uma estrutura de governança específica composta por três dimensões: 1) oportunidades de ações; 2) interesses dos atores; e 3) recursos de poder. Desta forma, os agentes envolvidos determinam suas ações (dentro do leque de possibilidades moldadas pelas regras ou normas) a partir de recursos e interesses, no contexto em que atuam. Assim, uma rede econômica, por exemplo, caracteriza-se pela interação cooperativa entre agentes em busca de um benefício econômico comum. A rede econômica se forma rapidamente em torno de uma emergente oportunidade de negócios e pode se dissipar com a mesma rapidez depois de cumprir seu curso. É uma rede com oportunidades de ações, interesse dos atores e recursos de poder específicos.

Segundo Sorensen (2007), as redes sociais caracterizam-se por um conjunto de agentes ligados por relações sociais de um tipo específico e são constituídas por dois elementos centrais: os atores e suas relações sociais. Os atores apresentam interesses específicos (político, financeiro, jurídico, tecnológico, entre outros) e utilizam-se dos recursos disponíveis para alcançar seus objetivos. As relações sociais, por sua vez, são caracterizadas pelo contexto em que os agentes estão envolvidos e são delimitadas pelas normas e regras institucionais.

Marques (1999) afirma que as redes sociais moldam as ações e as estratégias dos agentes, mas estas também estão sujeitas a um processo social dinâmico e contínuo. Da mesma forma, redes e identidades se constituem e se transformam mutuamente de uma forma complexa. Contudo, é importante 
ressaltar que a potencialidade da análise de redes não elimina a necessidade de utilização de outros atributos e estruturas formais, para que inúmeras outras perspectivas, como o neoinstitucionalismo, continuem extremamente relevantes.

A principal vantagem analítica na utilização da abordagem de redes é que ela amplia o conjunto de variáveis da realidade social que permaneciam até então obscuras, permitindo novos olhares sobre fenômenos pouco compreendidos, ou mesmo a construção analítica de novos objetos de estudo. Da mesma forma, a análise de redes tem possibilitado integrar economia e sociedade de uma maneira que recupera a melhor tradição de Max Weber e Karl Polanyi, como é o caso dos trabalhos de Granovetter (1973) e Burt (1992).

A chamada nova Sociologia Econômica, conforme designada por Granovetter (1985), busca a integração das teorias sociológicas e econômicas e se diferencia das demais correntes de pensamento das ciências sociais por privilegiar a dimensão histórica e os estudos empíricos. A nova Sociologia Econômica é baseada na ideia de que economia e sociedade são mutuamente enraizadas.

A abordagem de redes está relacionada, em maior ou menor grau, com várias abordagens sobre aglomerações produtivas. Nesta interface de diversas teorias para uma análise mais próxima da realidade observada nas aglomerações produtivas, a Sociologia Econômica oferece um valioso referencial analítico ao utilizar o próprio conceito de redes em análises como o de embeddedness de Granovetter (1985).

Segundo Granovetter (1985), o embeddedness das relações econômicas estaria fundamentado no poder estabelecido pela confiança recíproca para as interações sociais mais amplas que aquelas que dizem respeito exclusivamente a um dado estrato social. As ações econômicas são determinadas pelo modo como se dão as relações sociais nas quais essas ações estão imersas. Portanto, o contexto social é de fundamental importância para as interações dos agentes, incluindo aquelas de caráter econômico, baseadas na troca de bens e serviços.

Neste contexto, Granovetter (1985) afirma que a tarefa da sociologia econômica seria descrever o modo pelo qual as ações econômicas são estruturadas por meio de redes. Em suma, segundo o autor, as ações econômicas não acompanham os caminhos concisos e diretos da maximização, tal como reivindicam os economistas. As ações econômicas acompanham muito mais os caminhos consideravelmente mais complexos das redes existentes. Os economistas estavam errados, mas não tanto por conta de razões psicológicas correlacionadas ao homo economicus ou pelo quão racionais são as pessoas; os economistas falharam em apreender a importância da estrutura social na economia (SWEDBERG, 2004).

Putnam (2002), assim como Granovetter (1985), considera que a confiança entre os atores é de extrema importância no desenvolvimento de ações coordenadas. Este afirma que confiança, engajamento cívico, normas de reciprocidade e redes de interações sociais, cumprem a função de facilitar o surgimento de ações coordenadas e, portanto, de incrementar a eficiência de determinada comunidade. O capital social, por instituir a confiança generalizada, cumpre incrementar a cooperação voluntária em prol da ação coletiva favorecendo, por conseguinte, a resolução de problemas por essa via. Na reciprocidade generalizada, as relações envolvem bens e serviços de valores distintos de modo que o altruísmo é incentivado.

Com isso, percebe-se que certamente a análise econômica clássica não seria suficiente para explicar as diferenças de desenvolvimento local e as estruturas de governança no contexto de redes. A organização social e as instituições sociais são uma lacuna na economia neoclássica. Lá se considera o comportamento racional em mercados perfeitos. Entretanto, encontram-se casos de esforços teóricos para incorporar à visão econômica os conceitos qualitativos provenientes basicamente da sociologia como o conceito de capital social.

\subsection{A Rede política}

Segundo Börzel (1998), a utilização do conceito de redes políticas varia consideravelmente entre e dentro de diferentes disciplinas. Entretanto, estas diferenças compartilham de uma definição básica, definida como:

[...] um conjunto de relacionamentos relativamente estáveis, que não são hierárquicos e que possuem

Quadro 1. Características da Rede Política (policy network).

\begin{tabular}{|l|l|}
\hline Características dos membros & Características das conexões \\
\hline 1. conhecimento/informação & 1. regras \\
\hline 2. legitmidade & 2. centralidade \\
\hline 3. reputação & 3. intensidade \\
\hline 4. cooperação & 4. velocidade \\
\hline 5. habilidade para a mudança & 5. formalidade/informalidade \\
\hline
\end{tabular}

Fonte: Mello (2004). Elaborada a partir de Dowding (1995). 
uma natureza interdependente, ligando uma variedade de atores que compartilham interesses comuns no que diz respeito a uma política e que trocam recursos para prosseguir esses interesses partilhados, reconhecendo que a cooperação é a melhor maneira de alcançar objetivos comuns (BÖRZEL, 1998, p. 260).

Klijn (1998) considera as redes políticas como padrões mais ou menos estáveis de relações sociais entre atores interdependentes, que tomam forma ao redor dos problemas e/ou dos programas de políticas. Desta forma, as redes de políticas públicas formam o contexto no qual tem lugar o processo político e, consequentemente, promove a ligação entre o contexto e o processo de construção das políticas (KLIJN, 1998).

Segundo Waarden (1992), os atores são levados a estabelecer uma interação estratégica que reduz o custo de transação. A interação dos agentes reduz os esforços contínuos na busca por informações e gera acessos e influências nas decisões relativas à empresa. Os atores públicos poupam custo da coleta de informações e esforço para conquistar cooperação e assistência. Com isso, a emergência, estrutura e estabilidade da rede dependem das condições da organização, caracterizada pelo comportamento oportunista do agente, da incerteza econômica, das frequências das transações e da especificidade dos ativos.

A interação dos agentes leva a ligações entre os membros da rede, identificadas como conexões. A rede política é entendida como uma construção social e política, definida a partir de conexões complexas entre organizações distintas e dependentes de recursos como informação, regras, controle, reputação, legitimidade, agilidade, cooperação, etc. (PAULILLO, 2002).

Dowding (1995) identifica os fatores que podem caracterizar uma rede política pelos recursos de poder dos agentes por meio da legitimidade, da reputação, do conhecimento (busca por informações), da cooperação e da habilidade do agente para se adequar às mudanças, que leva a conexões marcadas pela centralidade, pela intensidade, por regras, pela velocidade das transações e pela formalidade ou informalidade. $\mathrm{O}$ Quadro 1 ilustra os fatores que podem caracterizar uma rede, segundo Dowding (1995).

Com as características dos membros e das conexões definidas, a abordagem das redes de poder permite ampliar a perspectiva de análise para vários setores ou regiões. Isto é possível porque uma rede de poder pode apresentar diversas estruturas de governança, seja mais fechada, integrada e institucionalizada até uma mais aberta, menos integrada e menos institucionalizada.

\subsubsection{Dimensões da rede política}

As dimensões são fundamentais para qualquer tipo de análise da rede. Na literatura referente ao tema, Waarden (1992) identifica sete dimensões da rede política. São elas:

- O número e o tipo de atores: são importantes para os atributos da rede e envolvem descritores como necessidades, interesses, estrutura, capacidade, recursos e desempenho (SACOMANO NETO, 2003);

- Função da rede: está ligada às necessidades, intenções, recursos e estratégias dos atores. Waarden (1992) destaca que o conceito de função representa uma ponte entre o ator e a estrutura da rede;

- Estrutura da rede: representa a forma de relação entre os atores e está ligada ao tamanho da rede; limites da rede (restrita ou acessível); estrutura das conexões (caótica ou ordenada); intensidade ou força da relação (frequência e duração da interação); densidade (densa ou múltipla); simetria ou reciprocidade da interconexão; tipo de coordenação, centralidade, grau de delegação e natureza das relações (confiança ou cooperativa);

- Institucionalização: é definida pelas características estruturais da rede e sua estabilidade. Redes fechadas tendem a apresentar maior institucionalização, com alta intensidade e com simetria de relações;

- Regras de conduta: são caracterizadas pelas convenções e interações ou regras do jogo que governam as trocas (SACOMANO NETO, 2003). Estas regras surgem a partir das percepções, atitudes e interesses dos atores envolvidos. As redes altamente institucionalizadas tendem a desenvolver suas próprias culturas e convenções;

- As relações de poder: são definidas a partir da distribuição dos recursos e das necessidades dos atores e pelas estruturas organizacionais presentes na rede;

- As estratégias dos atores: as estratégias de cada ator serão definidas em função das estratégias dos outros atores da rede. A interdependência dos atores na rede determina as estratégias de cada um.

\section{Metodologia de pesquisa}

Este trabalho é caracterizado por uma pesquisa exploratório-descritiva, dadas as características do objeto de estudo, da utilização do estudo de caso e do levantamento de dados. A pesquisa é predominantemente descritiva em sua essência, porém aborda um tema pouco explorado e utiliza-se de um estudo de caso, elementos típicos de uma pesquisa exploratória. $\mathrm{O}$ universo da pesquisa em arranjos 
produtivos locais é o próprio arranjo. Ou seja, o universo da pesquisa refere-se a uma única região. A pesquisa de campo caracteriza-se por um estudo de caso do APL de Jaú. A escolha do APL de Jaú se deve a vários fatores:

- Possui um número elevado de empresas do mesmo setor em uma mesma região;

- É um APL formado por empresas de diversos portes;

- Apresenta uma produção específica, focada em calçados femininos, o que coloca a APL em condições particulares de interesses, estratégias, concorrência e governança;

- Possui diversos atores (empresas, entidades de classes, poder público, etc.) e de segmentos, compreendendo praticamente toda a cadeia produtiva de calçados, desde o curtume até o varejo.

Ao analisar um único APL calçadista de maneira aprofundada, é possível desenvolver uma metodologia mais adequada às características do arranjo. Desta forma, a pesquisa de campo se inicia com a definição das dimensões a serem analisadas no estudo específico do APL de Jaú. Com base nas dimensões de redes estudadas no capítulo 1, Waarden (1992) destaca sete dimensões: número e o tipo de atores, função da rede, estrutura da rede, institucionalização, regras de conduta, relações de poder e estratégia dos atores. Marsh e Rhodes (1992) identificam como dimensões da rede: interesses; número e natureza dos membros; interdependência vertical e horizontal; e recursos de poder.

A partir das propostas de Waarden (1992) e Marsh e Rhodes (1992), para a análise da rede política do APL calçadista de Jaú, foram definidas as dimensões, seus descritores e seus indicadores, conforme o Quadro 2 a seguir.

A partir das dimensões de análise da rede foram selecionados os descritores destas dimensões e, logo em seguida, os indicadores que definem cada descritor com clareza. Faz-se necessário, portanto, definir cada descritor para a melhor compreensão da sua escolha e da ligação com os indicadores. Na dimensão dos atores, os descritores são autoexplicativos. Os tipos de interesses e os tipos de recursos dos atores provêm de interesses e de recursos políticos, financeiros, jurídicos e tecnológicos.

Na dimensão Estrutura das Relações, apresenta-se como descritor a centralidade da rede. A medida de centralidade é de fundamental importância para a identificação de agentes-chave na rede. A centralidade está relacionada com a atividade de um ator na rede e pode ser expressa pelo número de vínculos que este ator possui. Outra medida de centralidade está ligada à rapidez com que um ator interage com outros. Trata-se da centralidade por proximidade: quanto menor o número de "passos" para que um ator chegue a outro, maior sua proximidade (MELLO, 2004). A centralidade permite realizar a análise das ligações,

Quadro 2. Dimensões, Descritores e Indicadores da pesquisa.

\begin{tabular}{|c|c|c|}
\hline Dimensões & Descritores & Indicadores \\
\hline \multirow{2}{*}{ Atores } & Tipos de Interesses & $\begin{array}{l}\text { Político } \\
\text { Financeiro } \\
\text { Jurídico } \\
\text { Tecnológico }\end{array}$ \\
\hline & Tipos de Recursos Disponíveis & $\begin{array}{l}\text { Político } \\
\text { Financeiro } \\
\text { Jurídico } \\
\text { Tecnológico }\end{array}$ \\
\hline Estrutura das Relações & Centralidade & $\begin{array}{l}\text { Proximidade } \\
\text { Intermediação }\end{array}$ \\
\hline Estratégias dos atores & $\begin{array}{l}\text { Relacionamento do ator com } \\
\text { outros atores da rede }\end{array}$ & $\begin{array}{l}\text { Acesso dos grupos privados aos processos de } \\
\text { políticas públicas } \\
\text { Vantagens comparativas para certos grupos de } \\
\text { interesses, com acesso privilegiado perante o resto } \\
\text { Dependência do Estado com respeito aos recursos } \\
\text { dos grupos privados } \\
\text { Vontade de criar estruturas estáveis que reduzam } \\
\text { a incerteza do processo de elaboração de políticas } \\
\text { públicas }\end{array}$ \\
\hline Integração Política & Frequência & $\begin{array}{l}\text { Alta } \\
\text { Média } \\
\text { Baixa }\end{array}$ \\
\hline
\end{tabular}

Fonte: Elaborado pelos autores. 
identificando os indivíduos capazes de modificar a estrutura de comunicação existente na rede.

Neste sentido, pode-se destacar três tipos de centralidade: a centralidade de intermediação, a centralidade de proximidade e a centralidade por grau. A centralidade de intermediação (betweeness centrality) calcula o quanto um ator atua como ligação entre dois outros atores, facilitando o fluxo de informação em uma determinada rede. Este tipo de centralidade indica a frequência com que um ator está entre o canal de comunicação que conecta dois outros atores. A Centralidade de proximidade (closeness centrality) indica que um ator é tão mais central quanto menor o caminho que ele precisa percorrer para alcançar os outros elos da rede. Isso mede, em última análise, a sua independência em relação ao controle de outros, essa medida refere-se à distância que um ator está de outros. A proximidade mostra a facilidade de um ator em se comunicar com outros sem precisar de intermediários, compartilhando a informação diretamente com outros membros da rede (FAVA, 2009).

A dimensão Integração Política possui três descritores: frequência, continuidade e consenso. A frequência representa a quantidade de interações de troca ocorridas entre dois atores. Segundo Mello e Paulillo (2005), a frequência também expressa uma rica fonte de transferência de conhecimento tácito entre os indivíduos. Contatos pessoais permanentes adicionam certa dose de cortesia e consideração entre os atores, desencorajando ou, pelo menos, reduzindo, a possibilidade de busca de vantagens particulares numa transação.

Procurou-se, na elaboração do questionário privilegiar as questões fechadas. As questões fechadas são aquelas em que se apresenta ao respondente um conjunto de respostas para que ele indique a que melhor representa a sua opinião ou a situação abordada. As respostas foram classificadas em quatro categorias de intensidade: muito forte, forte, fraca ou ausente. Entretanto, manteve-se espaço para comentários opcionais do entrevistado, caso ele se disponha a detalhar a sua resposta.

\section{A rede política do APL calçadista de Jaú}

Depois da apresentação dos resultados da pesquisa empírica, faz-se necessário a análise destes resultados à luz das teorias estudadas. Este item apresenta a rede política do APL calçadista de Jaú, criada a partir do software UCINET. A análise da rede política está baseada nas dimensões e descritores propostos e é confrontada com as hipóteses do trabalho. As relações de poder delimitadas territorialmente na produção de calçados de Jaú proporcionam arranjos produtivos organizados localmente. Observa-se que há uma identidade cultural local e os atores estabelecem vínculos, mesmo que de intensidades diferentes, que proporcionam cooperação e aprendizagem entre si.

\subsection{Atores}

A rede apresentada na Figura 2 possui 41 atores e permite a identificação dos quatro elementos morfológicos: nós, posições, ligações e fluxos. Segundo as informações coletadas durante a pesquisa, há muitos outros nós na rede política real do APL calçadista de Jaú que não estão representados na Figura 2. Porém, estes nós ocupam posições relativamente periféricas na rede. A ausência destes nós não prejudica a identificação dos atores centrais e tampouco a análise completa da rede política.

$\mathrm{Na}$ identificação dos vínculos entre os atores que definem as relações políticas existentes, considerou-se que a ligação entre dois atores caracteriza um contato mútuo e não unilateral. Desta forma, o mesmo vínculo caracteriza dois atores da rede, multiplicando o número de ligações consideradas na análise. Nos fluxos estabelecidos, fluem basicamente informações que caracterizam os recursos envolvidos. Porém, apesar de o fluxo de informações ser o fluxo mais importante da rede política, não são raras as vezes em que ocorre fluxo de mercadorias e de recursos financeiros e tecnológicos. Desta forma, a posição de cada ator na rede é determinada pelo conjunto de vínculos estabelecidos com outros atores e, com isso, o acesso às informações, uso dos recursos e poder de influência nas decisões políticas do APL. Quanto mais central for a posição do ator na rede, maior deve ser o fluxo de informação compartilhado.

Os atores constituem a estrutura da rede, em que estão presentes as relações de poder, influência, interesses, confiança e as negociações. Os atores da rede política do APL calçadista de Jaú são numerosos e, na grande maioria, são empresas de pequeno porte e microempresas. Algumas destas empresas, porém, exercem influência considerável nas decisões do arranjo graças aos recursos políticos disponíveis.

Os atores mais influentes no processo decisório é o sindicato patronal Sindicalçados, entre outros motivos, por concentrarem grande parte do fluxo de informações do setor. Enquanto outras entidades de classe não são exclusivas do setor calçadista, como a Associação Comercial e Industrial, ou são ligadas a atividades de apoio ao setor, como a Assintecal, o Sindicalçados representa a indústria de calçadista local. Levando-se em conta o fato de que uma das características do APL calçadista de Jaú são as marcas próprias de varejo, as decisões tomadas na indústria influenciam fortemente o setor varejista de calçados local. Desta forma, o Sindicalçados possui poder político para impor suas decisões e orientar os rumos do APL. 


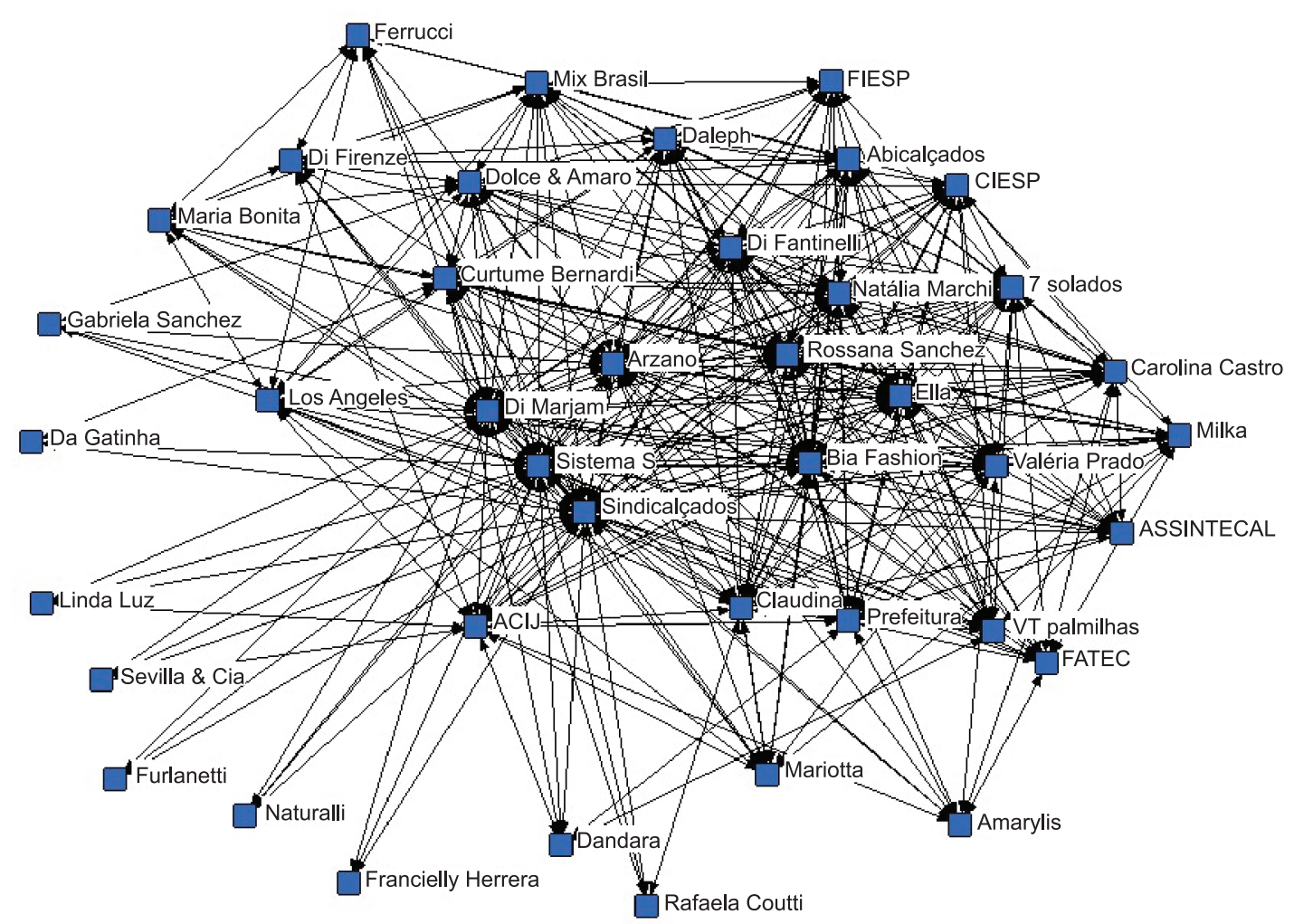

Figura 2. A Rede Política do APL calçadista de Jaú. Fonte: Elaborado pelos autores.

\subsection{Estrutura das relações}

A estrutura das relações entre os atores e a influência de alguns atores centrais na governança da rede são evidenciadas pela centralidade. A centralidade pode ser expressa pelo número de vínculos de um ator na rede e pode ser classificada em dois aspectos: centralidade por proximidade (closeness centrality) e centralidade de intermediação (betweenness centrality).

A pesquisa revelou uma influência política natural de alguns atores, em especial o Sindicalçados, pela concentração de recursos financeiros, jurídicos e tecnológicos. As empresas são levadas a se vincularem ao sindicato, por exemplo, por perceberem que estariam sob sua influência mesmo sem a formalização do vínculo. Os vínculos entre as empresas são informais, porém altamente eficientes e eficazes, como causa e consequência da confiança entre os atores. A afiliação à rede, portanto, é voluntária e considerada como natural pelos atores. Entretanto, apesar da afiliação voluntária, as relações são consideradas ordenadas por atores centrais que estabelecem a governança da rede política. A governança é influenciada pela existência de atores com grande influência nas decisões coletivas.

A centralidade por proximidade é calculada pela soma da distância geodésica de um nó em relação a todos os demais nós e depois se inverte, pois quanto maior a distância, menor é a proximidade. Esta medida indica que um ator é mais central quanto menor for o caminho que ele precisa percorrer para alcançar outros atores da rede.

Pela Figura 3, nota-se que o Sindicalçados e o Sistema S (exceto FIESP e CIESP) apresentam valores menores que os demais atores, indicando um caminho mais curto para alcançar outros atores da rede. Assim, pela centralidade de proximidade, tanto o Sindicalçados quanto o Sistema $\mathrm{S}$ assumem posições centrais na rede. A pesquisa revelou que atores como o Sindicalçados e o Sistema S mantêm vínculos diretos com a grande maioria dos atores. As empresas mais centrais são, majoritariamente, as ligadas ao Sindicalçados por meio de seus integrantes. A ACIJ e o curtume também apresentam posições de destaque, mesmo não sendo parte integrante do sindicato patronal.

Ao se considerar apenas os contatos do Sindicalçados na rede política e apenas os contatos do Sistema S, obtém-se como resultado uma figura muito semelhante à rede política original, o que demonstra o grande número de contatos diretos destes dois atores. Desta forma, pela centralidade por proximidade, tanto o Sindicalçados quanto o Sistema S se estabelecem como atores centrais na rede política. 


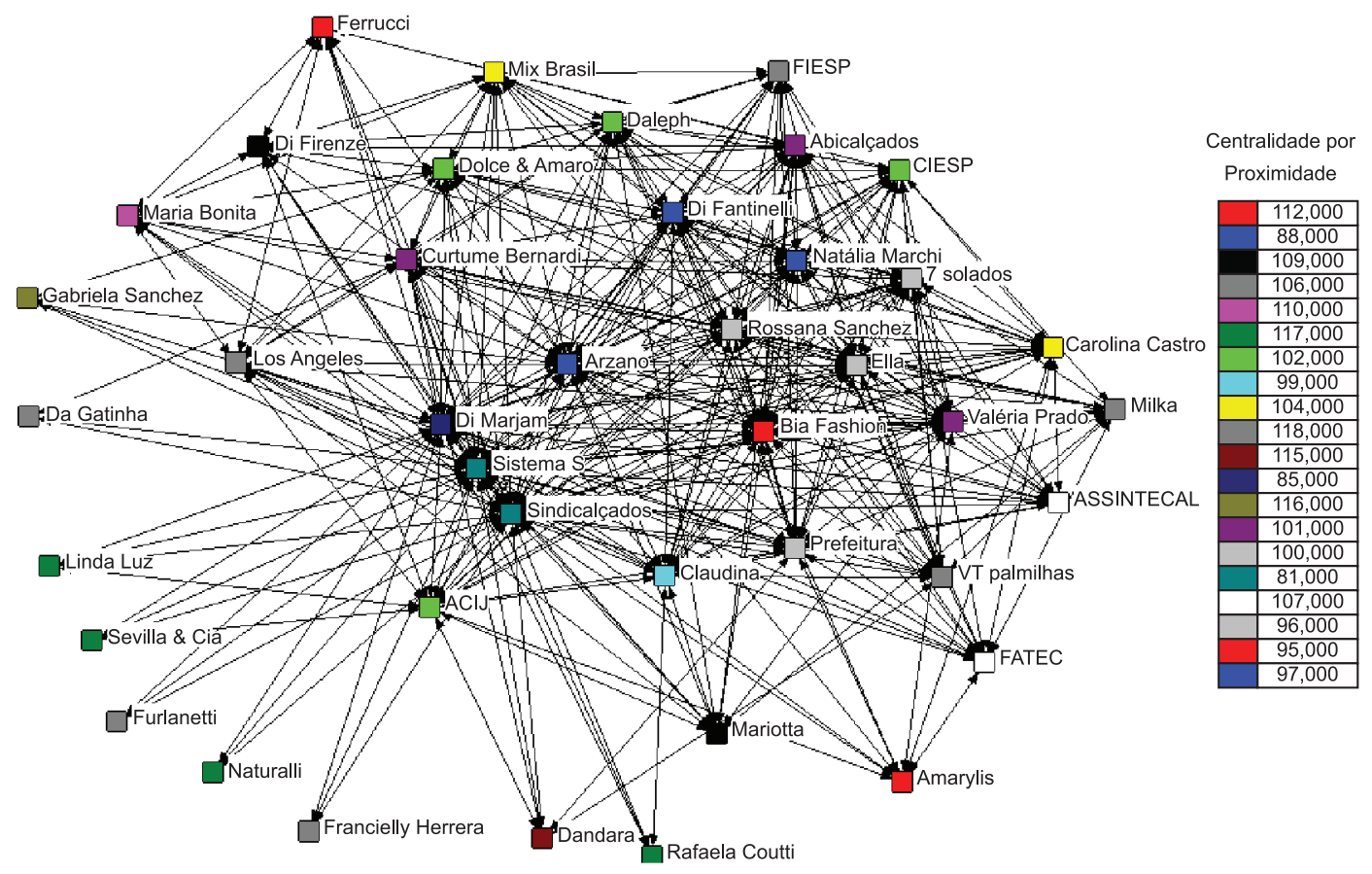

Figura 3. Centralidade por proximidade dos atores da rede política do APL calçadista de Jaú. Fonte: Elaborado pelo autor, através do software UCINET 6.0.

Na Figura 3, nota-se também a existência de algumas empresas mais centrais do que outras, revelando sua situação em relação às ligações da rede política. As empresas mais centrais são, majoritariamente, as ligadas ao Sindicalçados por meio de seus integrantes. A ACIJ e o curtume também apresentam posições de destaque, mesmo não sendo parte integrante do sindicato patronal.

A centralidade por intermediação (betweenness centrality) representa quanto um ator atua como ligação entre dois outros atores, facilitando o fluxo de informação na rede. Em outras palavras, as ligações entre dois atores dependem do número de nós existentes entre si. Quanto maior for o número de nós, mais intermediários existirão entre dois atores, dificultando as ações conjuntas. $\mathrm{O}$ índice de centralidade de intermediação, apontado na legenda, calcula, para cada nó, a soma de probabilidades de o referido nó estar no caminho entre todos os demais nós da rede. Desta forma, quanto maior o resultado calculado, maiores são as chances de o ator estar no caminho que liga dois outros atores.

Neste aspecto, por apresentarem grande número de ligações diretas, tanto o Sindicalçados quanto o Sistema $\mathrm{S}$ mais uma vez apresentam uma posição de destaque por possuírem grande parte dos contatos com os atores da rede sem nenhum tipo de intermediação. Pela Figura 4, percebe-se o Sindicalçados como o ator com um grau de intermediação maior que os demais, seguido pelo Sistema S e DiMarjam. Neste aspecto, a influência política de cada ator se torna mais evidente na medida em que este se torna referência de outros atores na busca pelos recursos almejados.

\subsection{Estratégia dos atores}

Apesar de a cadeia produtiva de calçados ser orientada pela demanda, as vendas e a produção estão diretamente ligadas ao APL de Jaú. Isto se explica pela existência de marcas próprias e pelo fato de a produção de calçados femininos ser fortemente influenciada pelas novas coleções em cada estação. Assim, a divulgação das novas coleções é fundamental para ampliar as vendas. A atratividade das novas coleções está centrada em tendências de cores, design e preços. Portanto, a informação acerca das tendências da moda, o design e o custo são variáveis fundamentais para os produtores e comerciantes de calçados femininos do APL.

Esta constatação é importante para a compreensão do relacionamento entre os atores do APL. Nota-se uma dependência de recursos financeiros por parte das empresas que é suprida com relativa facilidade pelos órgãos de fomento e pelo governo estadual. Isto se explica pelos interesses em comum e pela influência dos atores centrais da rede política. Ou seja, o acesso a órgãos de fomento ocorre sem grandes obstáculos, como BNDES, Secretaria do Desenvolvimento do Estado de São Paulo e SEBRAE. A disponibilidade de recursos financeiros, no entanto, é limitada. Os 


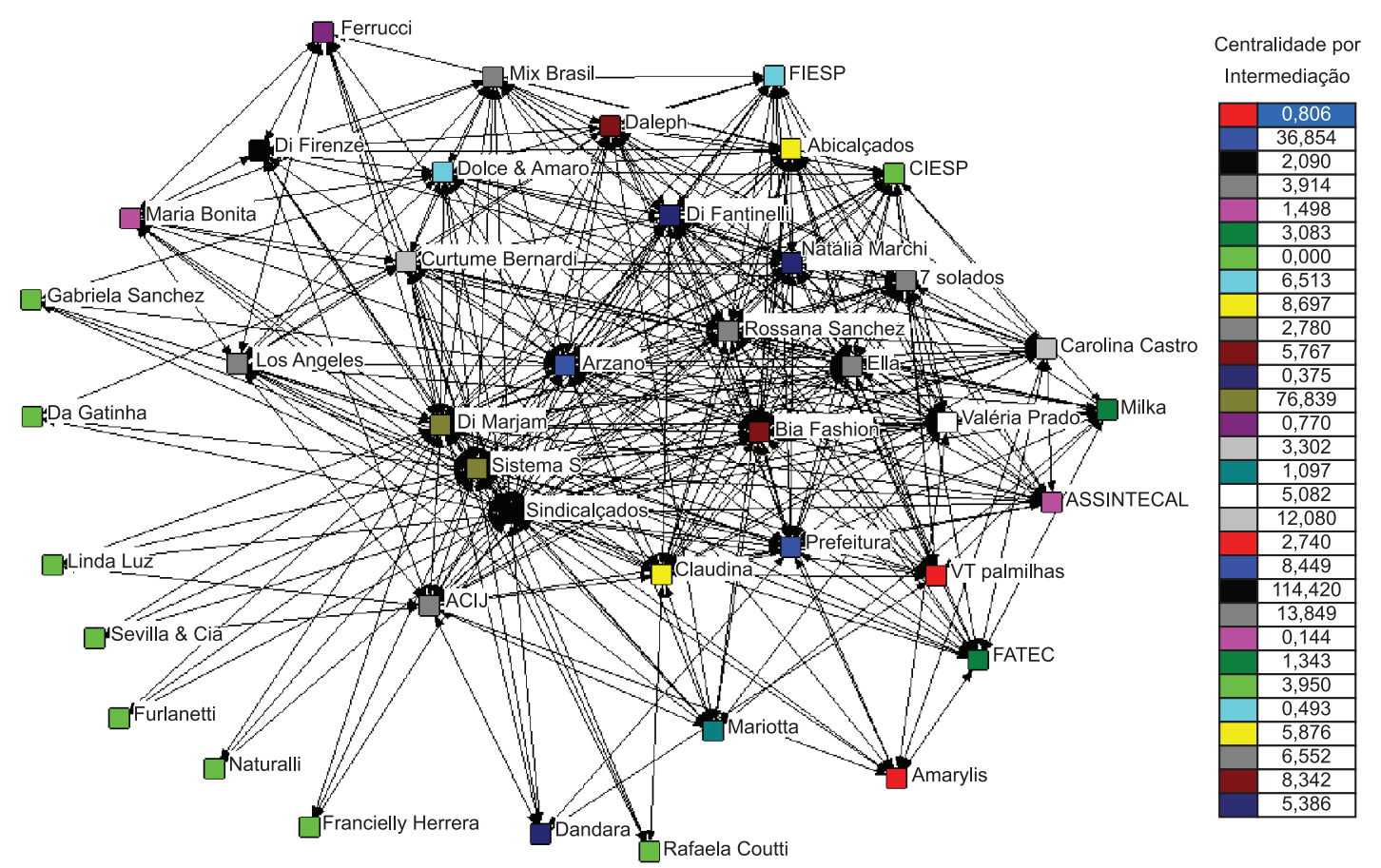

Figura 4. Centralidade por intermediação na rede política do APL calçadista de Jaú. Fonte: Elaborado pelo autor.

recursos costumam fluir por meio de iniciativas em parceria de atores do APL. O Sindicalçados, a Prefeitura e o Sistema S são os atores que mais promovem projetos em conjunto e buscam recursos nos órgãos citados.

Embora seja comum este tipo de parceria entre Sindicalçados, prefeitura e o Sistema S, as decisões técnicas costumam ficar a cargo do Sindicalçados, como a forma de promoção de eventos, as necessidades dos produtores e a determinação do público-alvo. À prefeitura cabe a disponibilidade de espaço físico, infraestrutura e suporte técnico em geral. Por sua vez, os atores do Sistema S têm, nas carências das empresas, a oportunidade de ampliar o seu escopo e promover a geração de conhecimento para suprir estas carências. Neste sentido, nota-se que as empresas ligadas ao Sindicalçados apresentam maior facilidade e rapidez no acesso à informação. Ao se considerar a baixa representatividade histórica das empresas na composição do Sindicalçados, nota-se a existência de um grupo de empresas com acesso privilegiado às informações.

Entretanto, o privilégio citado consiste basicamente no tempo de acesso às informações. Naturalmente, as empresas representadas no Sindicalçados têm acesso às informações antes dos demais atores. Embora seja um privilégio, isto não representa, porém, uma retenção das informações por parte destas empresas. Manter o fluxo de informações eficiente é de fundamental importância para a articulação dos atores do APL, tanto por uma tradição histórica quanto para que todos os atores se sintam como participantes do processo decisório.

A importância da inovação do design dos calçados ressalta a influência dos atores do Sistema $\mathrm{S}$ e das demais instituições de ensino específico do setor calçadista. Embora as empresas não sejam dependentes destes atores para produzir produtos com design inovadores, os atores do Sistema S mantêm uma ligação direta com a indústria local e de outros setores, adequando inovações aliadas a uma preocupação com os custos de fabricação. Assim, os recursos tecnológicos do Sistema S são voltados para o benefício dos atores do APL sem, a priori, uma distinção de grupos privilegiados. Porém, mais uma vez, a existência de membros em comum em empresas, Sindicalçados e entidades como FIESP e CIESP facilita o conhecimento e o acesso a estes recursos.

\subsection{Integração política}

A integração política entre os atores da rede foi analisada com base em três descritores: frequência, continuidade e consenso. A frequência na rede política é de fundamental importância para a análise da transferência de conhecimento tácito entre os atores. Na medida em que várias ações de cooperação são observadas entre os atores do APL de Jaú, a transferência de conhecimento tácito entre os atores ocorre de forma natural e legitimada por uma tradição nas relações entre os atores. Ao se considerar os atores centrais da rede, observa-se a troca constante 
de informações baseadas na busca por recursos e em orientações de conduta para a resolução de um problema específico. A convivência dos atores em um espaço geográfico característico como o APL de Jaú, com suas tradições e normas construídas ao longo do desenvolvimento do setor calçadista local, estimula as interações de troca entre os atores.

Justamente por constituir um espaço geográfico característico, com tradições bem definidas de conduta dos atores, nota-se uma continuidade significativa na rede política. Evidentemente, pode-se destacar, ao longo do desenvolvimento histórico do APL, fatos que provocaram oscilações na conexão entre alguns atores, especialmente no caso de atores periféricos. Entretanto, nenhum destes fatos constituiu uma descontinuidade das conexões a ponto de alterar profundamente as ligações entre os atores e modificar a estrutura das relações na rede política. A pesquisa revelou que os efeitos das interações entre os atores na rede, como as ações de cooperação e a troca de conhecimentos acerca da utilização dos recursos, são contínuos e significativos ao longo do tempo.

O consenso também é percebido na medida em que os atores afirmam sentirem-se participantes do processo de tomada de decisões por manterem contato com os atores que efetivamente tomam as decisões e são informados destas ações. Os atores legitimam as decisões tomadas, mesmo quando possuem opinião contrária, e se consideram participantes do processo decisório, mesmo quando não utilizam a facilidade de contato com os atores determinantes da decisão. É importante destacar que os conflitos de interesses ocorrem, porém, tradicionalmente, constituem conflitos localizados tanto no número de atores envolvidos quanto no tempo de duração, não representando um empecilho ao consenso na rede política.

\section{Considerações}

De acordo com a análise realizada com base nos indicadores da pesquisa, constatou-se a existência de uma Rede Política no APL de calçados femininos de Jaú. Os atores mais influentes na rede política do APL calçadista de Jaú são o Sindicalçados e os atores do Sistema S, como SENAI e SESI. Estes atores se destacam na rede política por concentrarem o fluxo de informação.

O Sindicalçados é um ator que congrega e representa os interesses da indústria calçadista local e possui membros em comum com diversas outras entidades, como FIESP e CIESP, e mantém ligações constantes com o poder público local e de fora do APL. O Sindicalçados concentra, portanto, os recursos políticos do APL como um todo. Já o poder político dos atores do Sistema S é proveniente da carência dos atores do APL de profissionais qualificados específicos do setor calçadista, que torna a qualificação profissional imprescindível para o desenvolvimento da produção e da comercialização do polo. Assim, apesar de os atores do Sistema $S$ que procuram suprir esta carência serem SESI, SENAI e SENAC, destacam-se também as atuações da FIESP e da CIESP, como centro de decisões no Sistema S.

A análise dos resultados da pesquisa revelou que os atores do Sistema S estão posicionados no centro da rede política do APL calçadista de Jaú. A centralidade se justifica pela forte dependência de profissionais qualificados e pela detenção de recursos tecnológicos fundamentais para a diferenciação dos produtos sem aumentos significativos de custo, sobretudo em um segmento fortemente influenciado por variações sazonais da moda. Esta dependência proporciona aos atores do Sistema S um ganho de poder político e a participação efetiva no processo de tomada de decisão do APL.

Entretanto, a pesquisa revelou que a rede política não se organiza somente em torno dos atores do Sistema S. O sindicato patronal também se posiciona como um ator central e detentor de recursos políticos elevados. O poder político do Sindicalçados, diferentemente do que ocorre com os atores do Sistema $\mathrm{S}$, foi acumulado por ser um ator representativo dos interesses dos demais atores. E este poder é potencializado quando os interesses representados pelo Sindicalçados coincidem com os interesses do poder público local e do Sistema S. A influência mútua nas decisões do Sindicalçados e do Sistema S é notória e está baseada em recursos políticos, como fonte para o acesso a outros recursos. É comum a participação do Sindicalçados na implantação de outros atores que desenvolvam recursos tecnológicos. Assim, embora haja certa distribuição dos recursos de poder, há a concentração do poder político no Sindicalçados, como arena das tomadas de decisões.

\section{Referências}

BÖRZEL, T. A. What's so Special About Policy Networks? An Exploration of the Concept and Its Usefulness in Studying European Governance. European Integration online Papers, v. 1, n. 16, 1997.

BÖRZEL, T. A. Organizing Babylon. On the Different Conceptions of Policy Networks. Public Administration, v. 76, n. 2, p. 253-73, 1998. http:// dx.doi.org/10.1111/1467-9299.00100

BRITO, J. Cooperação Interindustrial e Redes de Empresas. In: KUPFER, D.; HASENCLEVER, L. Economia Industrial: fundamentos teóricos e práticos no Brasil. Rio de Janeiro: Campus, 2002.

BURT, R. Structural Holes. Cambridge: Harvard University Press, 1992.

DOWDING, K. Model or metaphor? A critical review of the policy network approach. Oxford: Black Well Publishers, 1995. p.136-158. Political Studies. n. XLIII.

FAVA, F. E. Estudo do Arranjo Produtivo Local do álcool de Piracicaba através da análise de redes. In: CONGRESSO DE INICIAÇÃO CIENTÍFICA, 17.; 
MOSTRA ACADÊMICA, 7., 2009, Piracicaba. Anais... Piracicaba: UNIMEP, 2009.

GARCIA, R.; MOTTA, F. G.; AMATO NETO, J. Uma Análise das Características da Estrutura da Governança de Sistemas Locais de Produção e Suas Relações com a Cadeia Global. Gestão \& Produção, v. 11, n. 3, p. 343-354, 2004.

GRANOVETTER, M. The Strenght of Weak Ties: a network theory revisited. American Journal of Sociology, Chicago, v. 78, n. 6, p. 1360-1380, 1973.

GRANOVETTER, M. Economic Action and Social Structure: The Problem of Embeddedness. American Journal of Sociology, v. 91, n. 3, p. 481-510, 1985. http://dx.doi.org/10.1086/228311

HALL, M. Rethinking Collaboration and Partnership: a public policy perspective. Journal of Sustainable Tourism, v. 7, n. 3-4, p. 274-289, 1999. http://dx.doi. org/10.1080/09669589908667340

KLIJN, E. Policy Networks: an Overview. In: KICHERT, W. J. M.; KOPPENJAN, J. F. Managing Complex Networks. London: Sage, 1998.

LOMBARDI, M. The Evolution of Local Production Systems: the emergence of the "invisible mind" and the evolutionary pressures towards more visible "minds". Research Policy, v. 32, n. 9, p. 1443-1462, set. 2003 http://dx.doi.org/10.1016/S0048-7333(02)00157-9

MARQUES, E. C. Redes sociais e instituições na construção do Estado e da sua permeabilidade. Revista Brasileira de Ciências Sociais, v. 14, n. 41, 1999. http://dx.doi. org/10.1590/S0102-69091999000300004

MARSH, D.; RHODES, R. A. W. Policy communities and issue networks: beyond typology. In: MARSH, D.; RHODES, R. A. W. Policy networks in British government. Oxford: Clarendon Press, 1992. p. 249-269.

MELlo, F. O. Metamorfoses da Rede de Poder Sucroalcooleira do Estado de São Paulo: da regulação estatal para a desregulamentação. 2004. Dissertação (Mestrado)-Universidade Federal de São Carlos, São Carlos, 2004.

MELLO, F. O.; PAULILLO, L. F. O. Metamorfoses da Rede de Poder Sucroalcooleira Paulista e Desafios da
Autogestão Setorial. Agricultura São Paulo, v. 52, n. 1, p. 41-62, 2005.

NAVARRO YÁÑES, C. J. El sego participativo. Innovación democrática en municipios del sur de Europa (19601995). Córdoba: Consejo Superior de Investigaciones Científicas, 1999. (Colección Politeya, Estudos Política y Sociedad).

PAULILLO, L. F. O. Rede de relações e poder de negociação: uma análise do caso citrícola brasileiro. Gestão $\boldsymbol{\&}$ Produção, v. 8, n. 3, p. 250-270, dez. 2001. http://dx.doi. org/10.1590/S0104-530X2001000300004

PAULILLO, L. F. Redes de Poder e Territórios Produtivos. São Carlos: UFSCar, 2002.

POWELL, W.; SMITH-DOER, L. Networks and Economic Life. In: SMELSER, N.; SWEDBERG, R. The Handbook of Economic Sociology. 2nd ed. Princeton: Princeton University Press, 2003.

PUTNAM, R. Comunidade e Democracia -A Experiência da Itália Moderna. 3. ed. Rio de Janeiro: Fundação Getúlio Vargas, 2002.

SACOMANO NETO, M. Análise das redes: Estrutura e Relações. São Carlos: Universidade Federal de São Carlos - Departamento de Engenharia de Produção, 2003.

SANTOS, M. A natureza do espaço: técnica e tempo, razão e emoção. São Paulo: EdUSP, 2002.

SORENSEN, F. The geographies of social networks and innovation in tourism. Tourism Geographies, v. 9, n. 1, p. 22-48, 2007. http://dx.doi. org/10.1080/14616680601092857

SWEDBERG, R. Sociologia Econômica: hoje e ontem. Tempo Social, v. 16, n. 2, 2004.

WAARDEN, V. F. Dimensions and Types of Political Networks. Netherlands: Kluwer Academic Publisher. European Journal of Political Research, v. 21, p. 29-52, 1992. http://dx.doi. org/10.1111/j.1475-6765.1992.tb00287.x

WASSERMAN, S.; FAUST, K. Social Network Analysis: Methods and Applications. Cambridge: Cambridge University Press, 1994. 